Research Paper

\title{
The Beneficial Effect of Ginsenoside RgI on Schwann Cells Subjected to Hydrogen Peroxide Induced Oxida- tive Injury
}

\author{
Junxiong Ma\#, Jun Liu\#, Qi Wang, Hailong Yu, Yu Chen, Liangbi Xiang ${ }^{\bowtie}$ \\ Department of Orthopedics, General Hospital of Shenyang Military Area Command of Chinese PLA, Shenyang, 110016 Liaoning, China. \\ \# Junxiong Ma, and Jun Liu contribute equally to this work. \\ $\square$ Corresponding author: Liangbi Xiang, Department of Orthopedics, General Hospital of Shenyang Military Area Command of Chinese \\ PLA, Shenyang, 110016 Liaoning, China. Phone: 86-024-28856247; Fax: 86-024-28856247 Email: xiangliangbi1963@sina.com or cliff- \\ mjx@163.com.
}

(c) Ivyspring International Publisher. This is an open-access article distributed under the terms of the Creative Commons License (http://creativecommons.org/ licenses/by-nc-nd/3.0/). Reproduction is permitted for personal, noncommercial use, provided that the article is in whole, unmodified, and properly cited.

Received: 2013.01.16; Accepted: 2013.06.18; Published: 2013.06.29

\begin{abstract}
Ginsenoside RgI (GRgI) has been considered to have therapeutic potential in promoting peripheral nerve regeneration and functional recovery after sciatic nerve injuries. However, the mechanism underlying the beneficial effect of $\mathrm{GRgI}$ on peripheral nerve regeneration is currently unclear. The possible effect of GRgI on Schwann cells (SCs), which were subjected to oxidative injury after nerve injury, might contribute to the beneficial effect of GRgI on nerve regeneration. The present study was designed to investigate the potential beneficial effect of GRgI on SCs exposed to oxidative injury. The oxidative injury to SCs was induced by hydrogen peroxide. The effect of $\mathrm{GRgI}(50 \mu \mathrm{M})$ on SCs exposed to oxidative injury was measured by the levels of malondialdehyde (MDA), superoxide dismutase (SOD), glutathione (GSH) and catalase (CAT) in $\mathrm{SCs}$. The cell number and cell viability of SCs were evaluated through fluorescence observation and MTT assay. The apoptosis of SCs induced by oxidative injury was evaluated by an apoptosis assay. The expression and secretion of nerve growth factor (NGF) and brain-derived neurotrophic factor (BDNF) were evaluated using RT-PCR, Western blotting, and an ELISA method. We found that GRgI significantly up-regulated the level of SOD, GSH and CAT, and decreased the level of MDA in SCs treated with hydrogen peroxide. In addition, GRgI has been shown to be able to inhibit the proapoptotic effect of hydrogen peroxide, as well as inhibit the detrimental effect of hydrogen peroxide on cell number and cell viability. Furthermore, GRgI also increased the mRNA levels, protein levels and secretion of NGF and BDNF in SCs after incubation of hydrogen peroxide. Further study showed that preincubation with H89 (a PKA inhibitor) significantly inhibited the effects induced by hydrogen peroxide, indicating that the PKA pathway might be involved in the antioxidant effect and neurotrophic factors (NTFs) promoting effect of GRgI. In addition, a short-term in vivo study was performed to confirm and validate the antioxidant effect and nerve regeneration-promoting effect of GRgI in a sciatic crush injury model in rats. We found that $\mathrm{GRgI}$ significantly increased SOD, CAT and GSH, decreased MDA, as well as promoted nerve regeneration after crush injury. In conclusion, the present study showed that $\mathrm{GRg} I$ is capable of helping $\mathrm{SC}$ s recover from the oxidative insult induced by hydrogen peroxide, which might account, at least in part, for the beneficial effect of GRgI on nerve regeneration.
\end{abstract}

Key words: Ginsenoside Rg1 (GRg1); Schwann cell; hydrogen peroxide; oxidative injury.

\section{Introduction}

Ginsenoside Rg1 (GRg1), as one of the major bioactive components of ginseng, has been proved to possess dramatic neuro-protective and neuro-trophic effects in many studies [1-6]. Our previous in vivo 
study proved that GRg1 is capable of promoting peripheral nerve regeneration and functional recovery after sciatic nerve injuries [7]. However, the mechanism underlying the beneficial effect of GRg1 on peripheral nerve regeneration is currently unclear.

Schwann cells (SCs), as the only glial cells in peripheral nervous system, provide a permissive environment for peripheral nerve regeneration [8-9]. It has been well recognized that SCs can synthesize neurotrophic factors (NTFs) to provide trophic support for regenerating axons [8-9]. After peripheral nerve injuries, oxidative injury has been found to be involved in neural damage [10-11]. SCs are also the target of various oxidative stresses [12-15]. Therefore, oxidative injury of SCs has been deemed as an important process of peripheral nerve injury and repair. During the process of peripheral nerve injury, the oxidative stress around the injury site might impair the function of SCs, which might be detrimental to nerve regeneration and repair. Therefore, it is important to explore methods that can alleviate oxidative injury to SCs, which might be beneficial for nerve regeneration and functional recovery after nerve injury.

GRg1 has been proved to possess a notable anti-oxidative capability $[2,4,16,17]$. It has been shown that GRg1 can protect PC12 cells against apoptosis induced by dopamine or hydrogen peroxide by suppressing oxidative stress $[2,18]$. In addition, GRg1 has also been reported to protect substantianigra neuron against MPTP (1-methyl-4-phenyl-1,2,3,6tetrahydropyridine)-induced oxidative injury. Besides neural cells, GRg1 has been shown to reduce the exercise-induced oxidative injury of skeletal muscles and liver cells [19-20]. All these findings indicate that GRg1 is able to alleviate oxidative injury to different cell types. In a recent report, GRg1 has been demonstrated to promote expression of NTFs in normal primary SCs culture [21], indicating the beneficial effect of GRg1 on SCs. NTFs expression is one important physiological function of Schwann cells, especially during the process of nerve repair. The findings in previous study raise the possibility that GRg1 is capable of improving physiological function of SCs, which might contribute, at least in part, to the beneficial effect of GRg1 on nerve regeneration. However, the effect of GRg1 on SCs which were subjected to oxidative injury has not been investigated previously. Despite the fact that the neuroprotective effects of GRg1 have already been shown on neurons and some other cell types after oxidative injury induced by
$\mathrm{H}_{2} \mathrm{O}_{2}$, we still believe that examining the beneficial effect of GRg1 on SCs would add some value to the current existing knowledge.

The present study was designed to investigate the potential effect of GRg1 on SCs which were subjected to oxidative injury induced by hydrogen peroxide. The oxidative injury was evaluated by the levels of malondialdehyde (MDA), superoxide dismutase (SOD), glutathione (GSH) and catalase (CAT) in SCs. The cell number and cell viability of SCs were assayed by cell number counting and MTT assay. The apoptosis rate of SCs induced by oxidative stress was evaluated by an apoptosis assay. Finally, the expression and secretion of nerve growth factor (NGF) and brain-derived neurotrophic factor (BDNF) were evaluated using RT-PCR, Western blotting, and an ELISA assay. Furthermore, H89 (a PKA inhibitor) was used to investigate the possible involvement of PKA pathway. In addition, a short-term in vivo work has been done to investigate the effect of GRg1 on nerve regeneration in a crush nerve injury model of SD rat. The data of nerve regeneration and oxidative stress was collected to confirm and validate the antioxidant effect and beneficial effect of GRg1 in vivo.

\section{Materials and methods}

\section{Primary Schwann cell cultures}

The primary Schwann cell cultures were prepared using the protocol described in previous literature [22]. Details of the procedure are described briefly as follow. Sciatic nerves and brachial nerves were harvested from postnatal day 2 or 3 Sprague-Dawley rats (provided by Laboratory Animal Center of the Fourth Military Medical University, Xi'an, China). Then the nerves were digested with collagenase $(0.05 \%)$ and trypsin $(0.25)$ for $30 \mathrm{~min}$ at 37 ${ }^{\circ} \mathrm{C}$. The cells were centrifugated followed by incubation with $15 \%$ fetal calf serum (FCS, Gibco, Canada) and antibiotics in Dulbecco's modified Eagle's medium (DMEM). To inhibit fibroblast proliferation, the cells were treated with $10^{-5} \mathrm{M}$ arabinoside for $48 \mathrm{~h}$. Then the cells were incubated in DMEM, which contained 15\% FCS, $20 \mu \mathrm{g} / \mathrm{ml}$ bovine pituitary extract (Sigma, USA), $4 \mu \mathrm{M} / \mathrm{ml}$ forskolin (Sigma, USA), 100 $\mathrm{\mu g} / \mathrm{ml}$ streptomycin and $100 \mathrm{U} / \mathrm{ml}$ penicillin, under humidified $\mathrm{CO}_{2}$ at $37^{\circ} \mathrm{C}$. The third passage of SCs was used for the following experiments, and all the tests were repeated for five times. The purity of cells was identified using S-100 antibody (Santa Cruz, USA) (Fig. 1). 

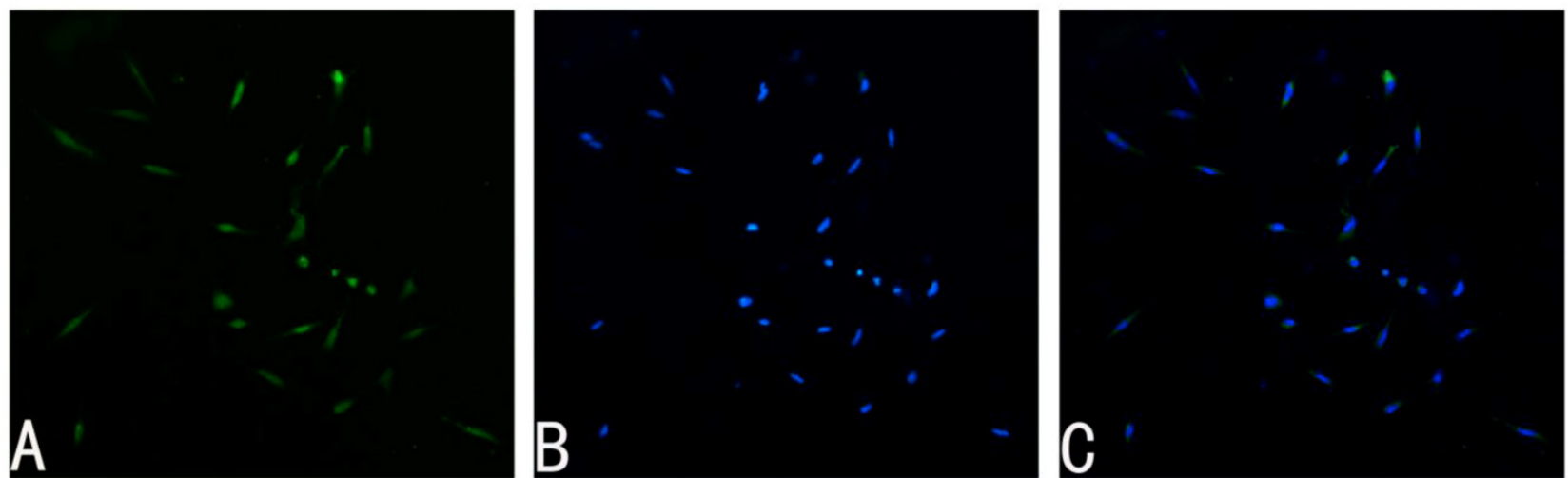

Fig I. Immunohistochemistry of primary SCs cultures. A: S-100 positive cells represent SCs. B: Nuclei were counterstained with DAPI (4,6-diamidino-2-phenylindole, $20 \mu \mathrm{g} / \mathrm{mL}$ in PBS). C: Merge file of A and B showed a purity of more than $95 \%$ SCs. Magnification was I00x.

\section{Hydrogen peroxide-induced oxidative injury model}

SCs (cell density: $1 \times 10^{6} / \mathrm{ml}$ ) were treated with hydrogen peroxide $\left(\mathrm{H}_{2} \mathrm{O}_{2}, 0.2 \%\right)$ for $4 \mathrm{~h}$. The culture medium containing $\mathrm{H}_{2} \mathrm{O}_{2}$ was replaced immediately by fresh medium with $50 \mu \mathrm{M}$ GRg1 (Fig. 2; purity> 98\%; National Institute for the Control of Pharmaceutical and Biological Products, Beijing, China), or 50 $\mu \mathrm{M}$ mecobalamin (Eisai, Tokyo, Japan; being widely used in the treatment of peripheral neuropathy and diabetic neuropathy), or normal saline (oxidative injury group) for $24 \mathrm{~h}$, respectively. To investigate the possible involvement of PKA pathway, SCs incubated with GRg1 were pre-incubated with or without $10 \mu \mathrm{M}$ H89 (a PKA inhibitor) for $1 \mathrm{~h}$. Normal SCs without any drug treatment were used as normal control group. Normal SCs pre-incubated with $10 \mu \mathrm{M}$ H89 for $1 \mathrm{~h}$ were used as H89 control group.

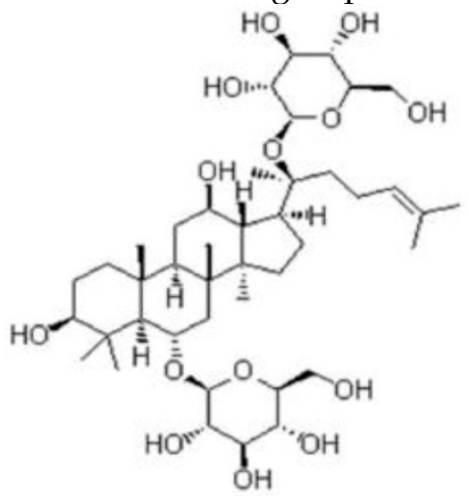

Fig 2. Chemical structure of GRgI.

\section{Oxidative stress}

\section{Assessment of lipid peroxidation}

At $24 \mathrm{~h}$ after incubation with GRg1, the level of malondialdehyde (MDA) in SCs in each group was detected to assess the level of lipid peroxidation.
Briefly, the MDA in the sample combined with thiobarbituric acid (TAB) at high temperature $\left(90-100^{\circ} \mathrm{C}\right)$. Then the MDA-TAB compound was measured at $450 \mathrm{~nm}$ by a spectrophotometer. The results are expressed as $\mu \mathrm{M} / \mathrm{mg}$ protein.

\section{Assessment of antioxidant enzyme activity}

To assess the level of antioxidant enzyme activity, superoxide dismutase (SOD) and catalase (CAT) of the SCs in each group were detected at $24 \mathrm{~h}$ after incubation with GRg1. The SOD was detected by using the xanthine oxidase. The absorbance was read at $450 \mathrm{~nm}$ using ELISA plate reader (Agilent, USA). CAT was examined by adding hydrogen peroxide, and the absorbance was read at $540 \mathrm{~nm}$. The activity of SOD and CAT was calculated per mg protein.

\section{Assessment of GSH}

At $24 \mathrm{~h}$ after incubation with GRg1, the glutathione (GSH) level in SCs was detected according to the protocol provided by the commercial kit (Amersham Biosciences, USA). The absorbance was read at $405 \mathrm{~nm}$. The results were calculated per mg protein.

\section{Cell number of SCs}

At $24 \mathrm{~h}$ after incubation with GRg1, fluorescence observation was performed to observe the cell number of the SCs. After being fixed regularly, the SCs were incubated with $3 \mu \mathrm{g} / \mathrm{ml}$ DAPI (4,6-diamidino-2phenylindole) for $10 \mathrm{~min}$. Then the SCs were washed by phosphate buffered saline (PBS) and cover-slipped with $50 \%$ glycerol buffer solution. The stained SCs were photographed using fluorescence microscope (Nikon TE2000-E, Japan). A drop of cell suspension was dropped in the hemocytometer. The cell numbers were counted. The concentration of cells per ml was recorded.

\section{MTT assay}

At $24 \mathrm{~h}$ after incubation with GRg1, MTT assay 
was performed to analyze cell viability. Briefly, $10 \mu \mathrm{l}$ of $5 \mathrm{mg} / \mathrm{ml}$ tetrazole in PBS was added to the media. After incubation for $4 \mathrm{~h}$ at $37^{\circ} \mathrm{C}, 150 \mu \mathrm{l}$ of dimethylsulfoxide (DMSO) was added. The OD values were measured using a micro-plate reader by absorbance changes at $550 \mathrm{~nm}$. The results were expressed as a percentage with the untreated control as $100 \%$.

\section{Apoptosis}

At $24 \mathrm{~h}$ after incubation with GRg1, the FACScan flow cytometry was used to measure the apoptosis of the SCs. Briefly, the SCs were suspended in binding buffer containing propidium iodide (PI) and AnnexinV-FITC, the concentration of which was specified by manufacturer (Sigma, USA). SCs were incubated in the dark for $5 \mathrm{~min}$ at $25^{\circ} \mathrm{C}$. FACScan flow cytometry (Becton Dickinson, San Jose, CA) was used to analyze the percentage of FITC-labeled cell membrane phosphatidylserine residues, as a measurement of apoptosis.

\section{Real time-polymerase chain reaction (RT-PCR)}

At $24 \mathrm{~h}$ after incubation with GRg1, the number of SCs was firstly counted in each group. The cells were then homogenized in Trizol Reagent (Sigma-Aldrich, US). Total RNA was extracted and normalized to cell number before RT-PCR was performed. Then RT-PCR was performed according to the manufacturer's instructions. The sequencers of primers for BDNF and NGF and $\beta$-actin are shown in Table 1 . The PCR reaction was conducted using $25 \mu 1$ of sample cDNA, $2.5 \mu \mathrm{l}$ of $10 \times$ PCR buffer, $2.0 \mu \mathrm{l}$ of $\mathrm{MgSO}_{4}(25 \mathrm{mM}), 2.5 \mu \mathrm{ldNTP} \operatorname{mix}(2 \mathrm{mM}), 0.5 \mu \mathrm{l} \mathrm{Taq}$ DNA Polymerase $(2 \mathrm{U} / \mu \mathrm{l})$, and $15.8 \mu \mathrm{l}$ deionized $\mathrm{H}_{2} \mathrm{O}$. The reaction mixture was heated to $95^{\circ} \mathrm{C}$ for 2.5 min and then amplified for 40 cycles as follows: $95^{\circ} \mathrm{C}$ for $35 \mathrm{~s}$ (denaturation), $54^{\circ} \mathrm{C}$ for $30 \mathrm{~s}$ (annealing), and $65^{\circ} \mathrm{C}$ for $5 \mathrm{~s}$ (extension). The results were normalized to cell number in each group.

Table I. Nucleotide sequence for oligonucleotide primers and size of the expanded PCR products.

\begin{tabular}{|c|c|c|c|}
\hline Gene & Primer & Sequence & $\begin{array}{l}\text { Product } \\
\text { (bp) }\end{array}$ \\
\hline \multirow[t]{2}{*}{ NGF } & Forward & 5'TCCACССАСССАGТСТТССАЗ' & 343 \\
\hline & Reverse & 5'GCCTTCCTGCTGAGCACACA3' & \\
\hline \multirow[t]{2}{*}{ BDNF } & Forward & 5'AGCTGAGCGTGTGTGACAGT3' & 252 \\
\hline & Reverse & 5'TCCATAGTAAGGGCCCGAAC3' & \\
\hline \multirow[t]{2}{*}{ GAPDH } & Forward & 5'CACCACCATGGAGAAGGCC $3^{\prime}$ & 190 \\
\hline & Reverse & 5'GATGGATGCCTTGGCCAGG3' & \\
\hline
\end{tabular}

\section{Western blotting}

At $24 \mathrm{~h}$ after incubation with GRg1, Western blotting was performed to examine the protein levels of $\beta$-NGF and BDNF. Briefly, cells were treated with lysis buffer which was supplemented with protease inhibitors (Promega, Madison, WI, USA). BAC assay was performed to measure the total protein concentration. The protein extracts were heat denatured, electrophoretically separated, and transferred to a PVDF membrane, at $100{ }^{\circ} \mathrm{C}$ for $5 \mathrm{~min}$. Then the PVDF membrane was blocked and incubated with Rabbit-Anti-Rat $\beta$-NGF antibody (1:2000, Santa Cruz, USA) and Rabbit-Anti-Rat BDNF antibody (1:2000, Santa Cruz, USA) overnight at $4{ }^{\circ} \mathrm{C}$. ThePVND membranes were washed with buffer and incubated with HRP-conjugated Goat-Anti-Rabbit IgG (1:500, Santa Cruz, USA) for $2 \mathrm{~h}$ at $25^{\circ} \mathrm{C}$. An ECL kit (USCNLIFE, USA) was used to measure the HRP activity. A GS 800 Densitometer Scanner (Bio-Rad, Hercules, CA, USA) was used to scan the membranes. The PDQuest 7.2.0 software (Bio-Rad, Hercules, CA, USA) was used to determine the density of the band. Rabbit-Anti-Rat $\beta$-actin polyclonal antibody (1:500, Santa Cruz, USA) was used as an internal control. The results were normalized to cell number in each group.

\section{Secretion of NGF and BDNF (quantification by ELISA)}

At $24 \mathrm{~h}$ after incubation with GRg1, ELISA was performed to measure the concentrations of NTFs in cellular supernatants. Briefly, the culture mediums of each groups were collected and centrifugated. Concentrations of BDNF and NGF, which were secreted by SCs, were measured using an ELISA kit following the manufacturer instructions (Santa Cruz, USA). The 96-well plate was examined using a microplate reader (Multiscan MK3, Thermo Labsystems, Finland) at the absorbance of $450 \mathrm{~nm}$. The results were normalized to cell number of each group.

\section{In vivo study (crush injury model of sciatic nerve of rat)}

Young adult male Sprague-Dawley rats $(\mathrm{n}=24$, weighing from $200 \mathrm{~g}$ to $220 \mathrm{~g}$, provided by the Laboratory Animal Center of the Fourth Military Medical University, Xi' an, China) were randomly divided into three groups ( $\mathrm{n}=8$ in each group; normal group, crush injury group, and crush injury+GRg1 group). A model of sciatic nerve crush injury was established according to the method described in our previous study [7]. The normal group only received sham operation. Following surgery, all animals were intraperitoneally administrated daily for 2 weeks with $5 \mathrm{mg} / \mathrm{kg}$ GRg1 (crush injury+GRg1 group) or saline (normal group and crush injury group). 
Two weeks after surgery, the regenerated nerve tissues were harvested for oxidative stress assessment $(n=4$ in each group). The levels of MDA, SOD, CAT and GSH in nerves tissue were detected as described above.

Four weeks after surgery, the regenerated nerves were harvested for nerve morphometric evaluations according to the method described in our previous study ( $\mathrm{n}=4$ in each group) [7]. Briefly, the tissues were fixed in $3 \%$ glutaraldehyde, and post-fixed in $1 \%$ osmium tetroxide. Then the samples were dehydrated by ethanol and embedded in resin. Transverse $1.0 \mu \mathrm{m}$ semi-thin sections and $50.0 \mathrm{~nm}$ ultra-thin sections were prepared from the distal portion of the samples. One complete cross-section was taken for every five continuous sections, until five complete cross-sections were collected. The semi-thin sections were stained with a $1 \%$ toluidine blue and $1 \%$ borax solution followed by being examined under a light microscope (AH3, Olympus, Tokyo, Japan). 50.0 nm Ultra-thin sections were stained with uranyl acetate and lead citrate followed by being examined under a transmission electron microscope (H-600, HITACHI, Tokyo, Japan). Morphometric evaluations were done by people who were blind to the design of the experiment. Axonal regeneration was estimated by the mean diameter of nerve fibers, the total number of myelinated axons per nerve transverse section, and total area of regenerated axons. The axon to fiber diameter ratio (G-ratio) was calculated to estimate the degree of myelination.
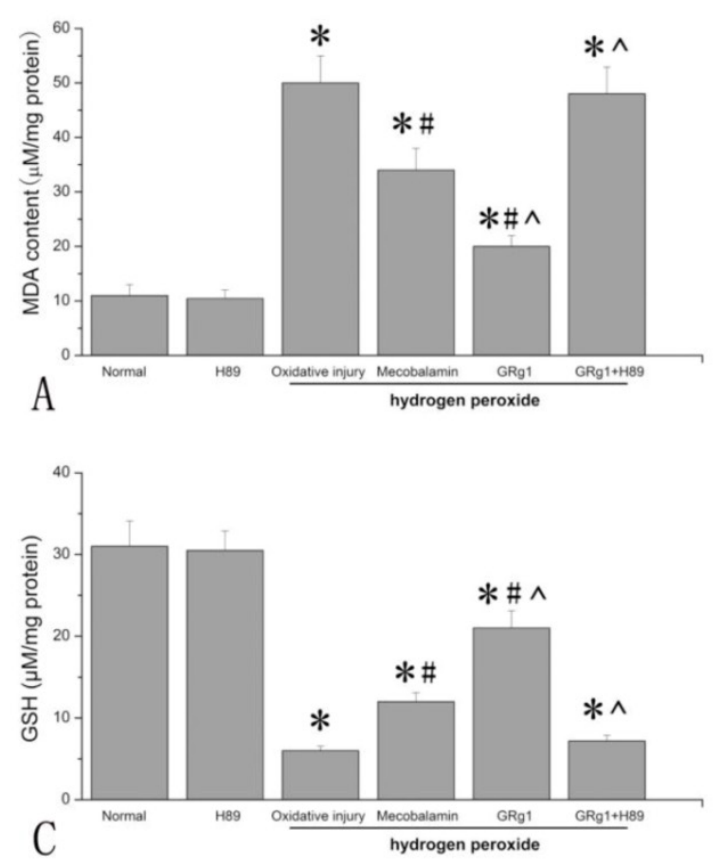

\section{Statistical analysis}

All data are presented as the mean \pm standard error of mean (S. E. M). One-way analysis of variance (ANOVA) and ANOVA for repeated measurements were used to compare mean values using the SPSS13.0 software (SPSS Inc., Chicago, IL, USA). If there was a significant overall difference among groups, Tukey post hoc test was used to make pair-wise comparisons. Values of $p<0.05$ were considered statistically significant.

\section{Results}

\section{GRg I attenuates hydrogen peroxide-induced oxidative injury}

The hydrogen peroxide-induced oxidative injury was estimated by measuring the levels of MDA, SOD, GSH and CAT in SCs. As shown in Fig. 3 A, the MDA level in SCs treated with hydrogen peroxide was significantly higher than that in normal SCs without hydrogen peroxide $(p<0.05$, Fig. 3 A), indicating increased lipid peroxidation induced by hydrogen peroxide in SCs. When hydrogen peroxide-treated SCs were incubated with GRg1 or mecobalamin, the MDA levels were significantly decreased, with a decrease of $60 \%$ by GRg1 and $32 \%$ by mecobalamin. Additionally, the MDA level was significantly lower in the GRg1-treated SCs than that in the mecobalamin treated SCs ( $p<0.05$, Fig. 3 A). However, the attenuating effect of GRg1 on lipid peroxidation was significantly inhibited by pre-incubation with H89 (Fig. 3 A).
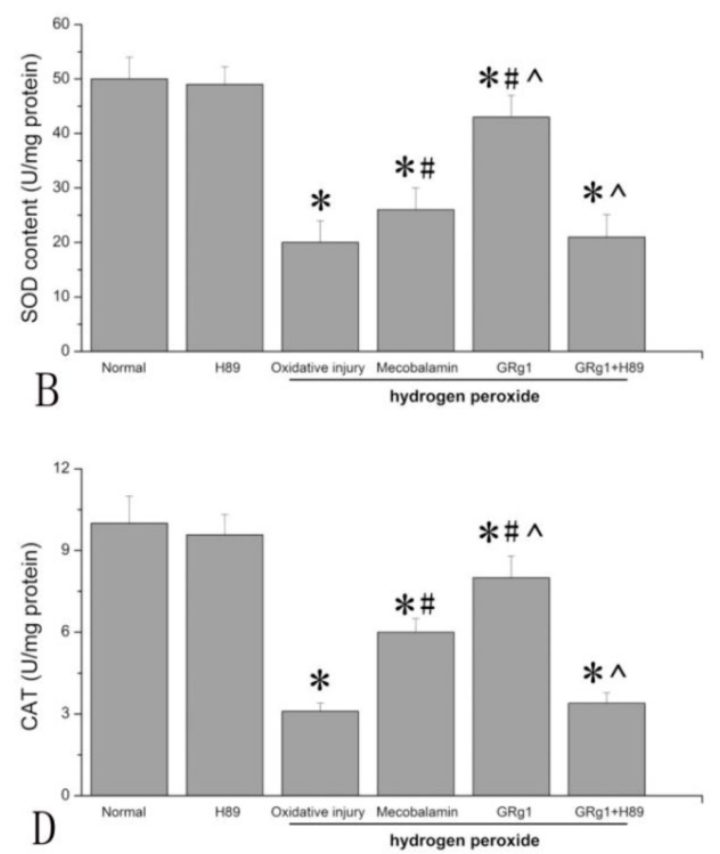

Fig 3. The MDA level (A), SOD activity (B), GSH level (C) and CAT activity (D) in each group after hydrogen peroxide-induced oxidative injury. ${ }^{*} p<0.05$ for the comparison with normal group. ${ }^{*} p<0.05$ for the comparison with oxidative injury group. ${ }^{\wedge} p<0.05$ for the comparison with mecobalamin group. 
The SOD activity, CAT activity and GSH level were also measured to investigate the oxidative injury to SCs induced by hydrogen peroxide. It was found that hydrogen peroxide significantly decreased the SOD activity, CAT activity and GSH level in SCs $(p<$ 0.05, Fig. 3 B, C, D), indicating decreased antioxidant activity in SCs incubated with hydrogen peroxide. When hydrogen peroxide-treated SCs were incubated with GRg1 or mecobalamin, the SOD activity, CAT activity and GSH level were significantly increased, with an increase of $115 \%$ for SOD, $177 \%$ for CAT, $208 \%$ for GSH by GRg1, and 34\% for SOD, $102 \%$ for CAT and $95 \%$ for GSH by mecobalamin $(p<0.05$, Fig. 3 B, C, D). Further analysis showed that the SOD activity, CAT activity and GSH level in the GRg1-treated SCs were significantly higher than that in the mecobalamin-treated SCs $(p<0.05$, Fig. 3 B, C, D). However, the beneficial effect of GRg1 on the SOD activity, CAT activity and GSH level were significantly inhibited by pre-incubation with H89 (Fig. 3 B, C, D).

To further investigate the role of SOD in the beneficial effect of GRg1 on hydrogen peroxide exposed SCs, the cells were treated with PEG-SOD (100 $\mathrm{U} / \mathrm{ml}$ ) after treatment of hydrogen peroxide, and the cell viability was examined. The results showed that PEG-SOD increased the cell viability of SCs, with an
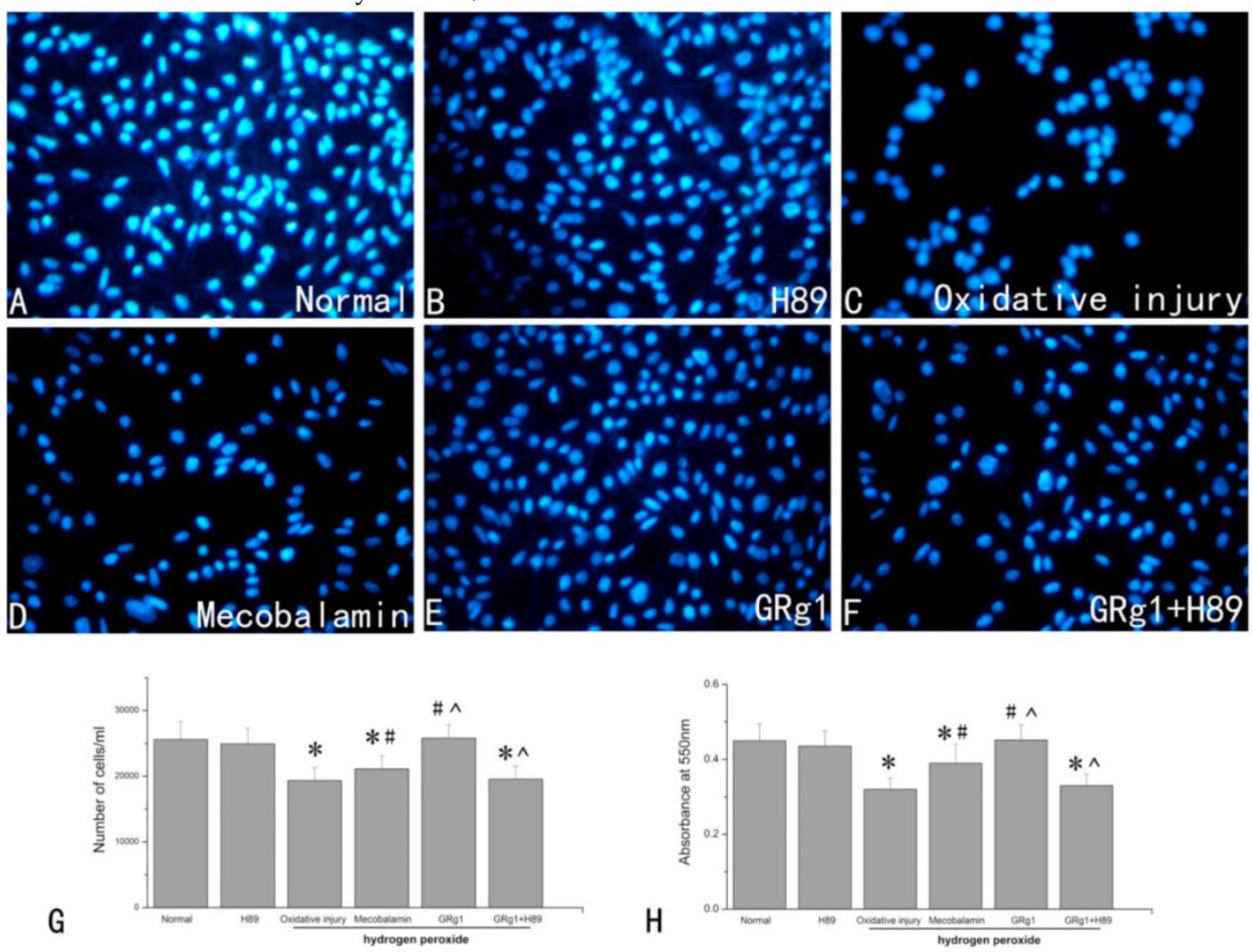

Fig 4. Cell number (A-G) and cell viability $(\mathbf{H})$ of SCs in each group after hydrogen peroxide-induced oxidative injury. SCs were visualized by DAPI staining in the normal group (A), H89 group (B), oxidative injury group (C), mecobalamin group (D), GRgI group (E), and GRgI +H89 group (F). Magnification was $200 x$. The number of stained SCs (E). $* p<0.05$ for the comparison with normal group. ${ }^{*} p<0.05$ for the comparison with oxidative injury group. $\wedge_{p}<0.05$ for the comparison with mecobalamin group. 
Hydrogen peroxide significantly $(p<0.05$, Fig. 4 $\mathrm{H})$ decreased the cell viability of SCs, with a decrease of $28.9 \%$ compared to that in normal SCs cultured without hydrogen peroxide. When GRg1 or mecobalamin was added to the hydrogen peroxide treated SCs, the cell viability was significantly increased by GRg1 or mecobalamin compared to that in SCs only treated with hydrogen peroxide $(p<0.05$, Fig. $4 \mathrm{H})$. We also observed significantly higher cell viability in the GRg1 group than that in the mecobalamin group $(p<0.05$, Fig. $4 \mathrm{H})$. No difference was observed in cell viability between the GRg1 group and normal group $(p>0.05$, Fig. $4 \mathrm{H})$. However, the beneficial effect of GRg1 on cell viability was significantly inhibited by pre-incubation with H89 (Fig. $4 \mathrm{H}$ ).

\section{GRg I inhibits hydrogen peroxide-induced proapoptotic effect on SCs}

The percentage of apoptotic cells was examined by an apoptosis assay. It was found that a significantly higher number of apoptotic SCs was induced by hydrogen peroxide, indicating that treatment with hydrogen peroxide is capable of inducing cell apoptosis $(p<0.05$, Fig. 5 A, C, G). When the hydrogen peroxide-treated SCs were treated with GRg1 or mecobalamin, the percentage of apoptotic cells was significantly decreased by GRg1 or mecobalamin compared to that in SCs only treated with hydrogen peroxide $(p<0.05$, Fig. 5 C, D, E, G). In addition, we also observed significantly higher percentage of apoptotic cells in the mecobalamin group than that in the GRg1 group ( $p<0.05$, Fig. 5 D, E, G). Furthermore, the percentage of apoptotic cells was in the similar range between the GRg1 group and normal group $(p>$ 0.05, Fig. 3 A, E, G). However, the inhibitory effect of GRg1 on apoptosis induced by hydrogen peroxide was significantly inhibited by H89 (Fig. 5 F, G).

\section{GRg I increased expression and secretion of NGF and BDNF}

At the mRNA level, GRg1 significantly increased the expression of NGF and BDNF in SCs compared to the cells cultured under normal condition, the cells cultured with hydrogen peroxide, or the cells cultured in the presence of hydrogen peroxide and mecobala$\min (p<0.05$, Fig. 6 A; $p<0.05$, Fig. 6 B). The mRNA levels of NGF and BDNF were in the similar range among the cells cultured under normal condition, the cells cultured with hydrogen peroxide, and the cells cultured in the presence of hydrogen peroxide and mecobalamin $(p>0.05$, Fig. $6 \mathrm{~A}, \mathrm{~B})$. The beneficial effect of GRg1 on NTFs at the mRNA level was abolished by pre-incubation with H89 (Fig. 6 A, B).

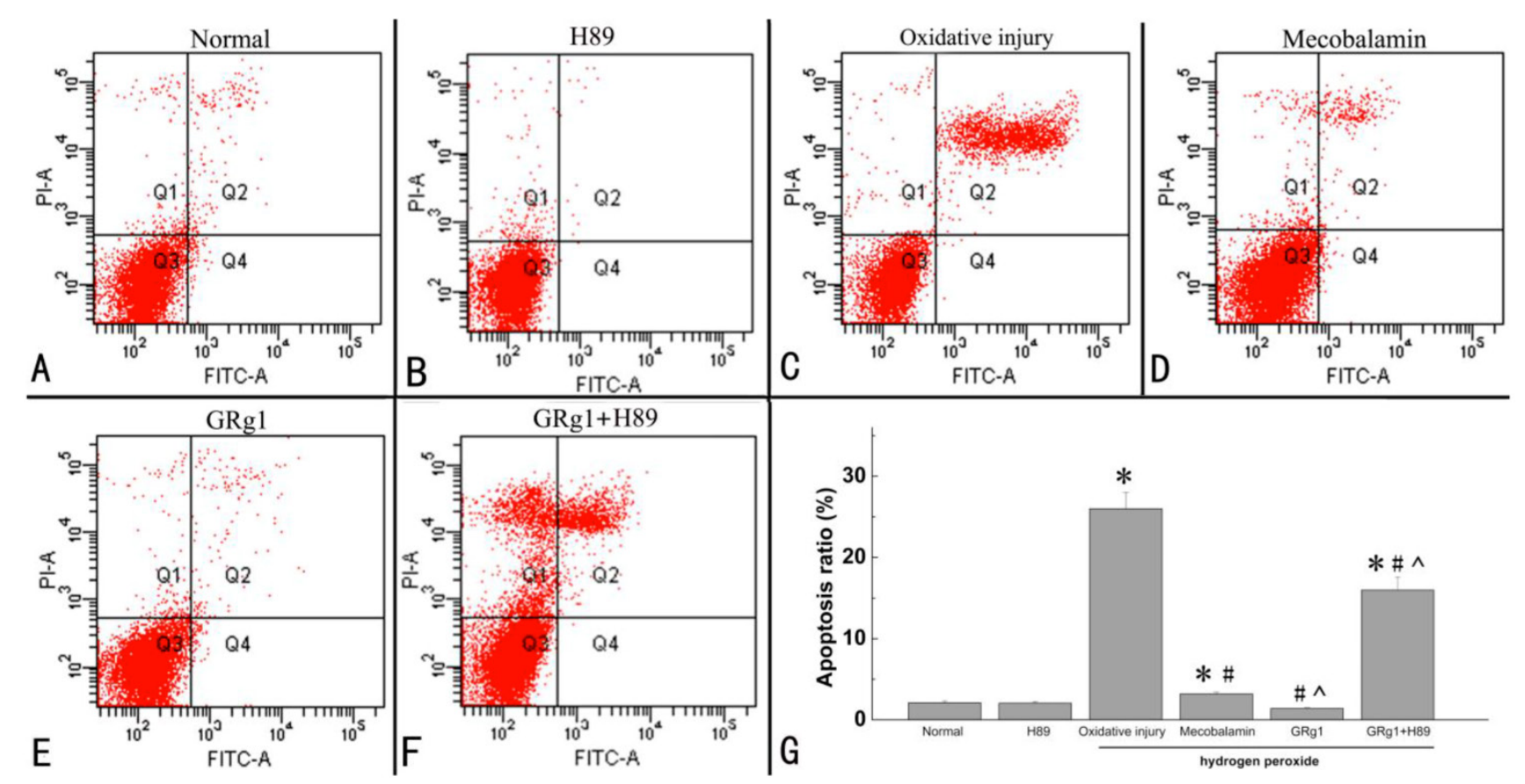

Fig 5. Apoptosis of SCs in each group after hydrogen peroxide-induced oxidative injury. The apoptosis rate (G) of $\mathrm{SCs}$ in normal group (A), H89 group (B), oxidative injury group (C), mecobalamin group (D), GRgI group (E), and GRgI+H89 group (F) were shown. *p $<0.05$ for the comparison with normal group. ${ }^{\#} p<0.05$ for the comparison with oxidative injury group. $\wedge_{p}<0.05$ for the comparison with mecobalamin group. 

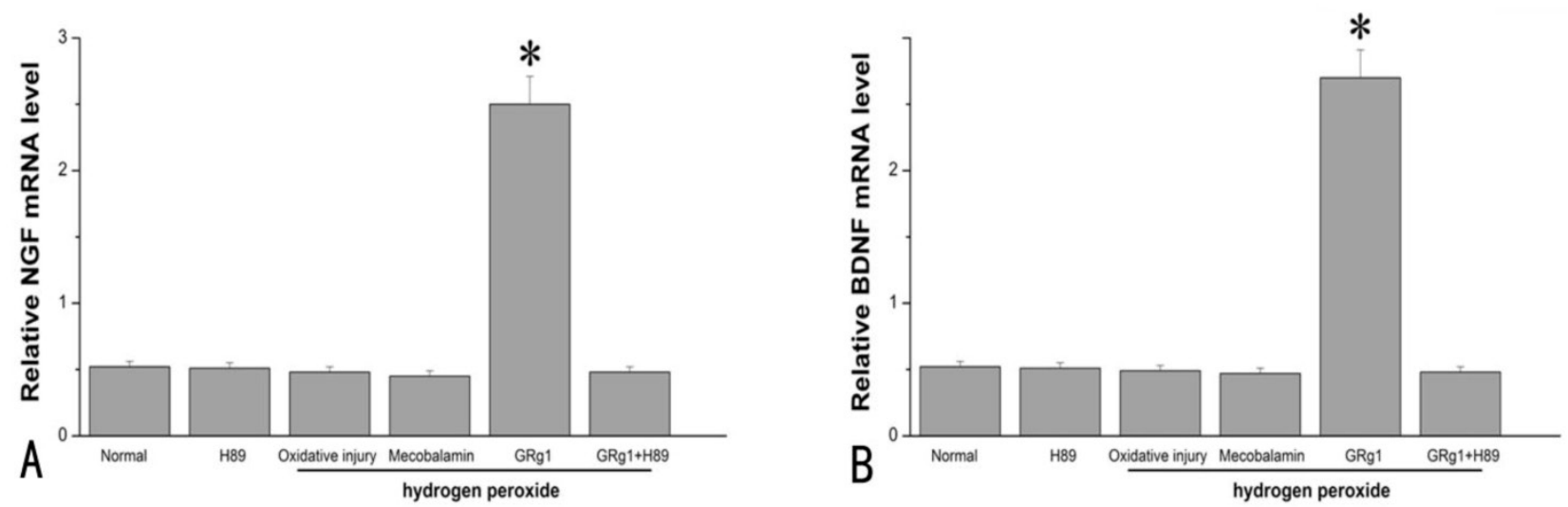

Fig 6. The mRNA levels of NGF (A) and BDNF (B) in SCs after hydrogen peroxide-induced oxidative injury. $* p<0.05$ for the comparison with normal group, oxidative injury group, or mecobalamin group.
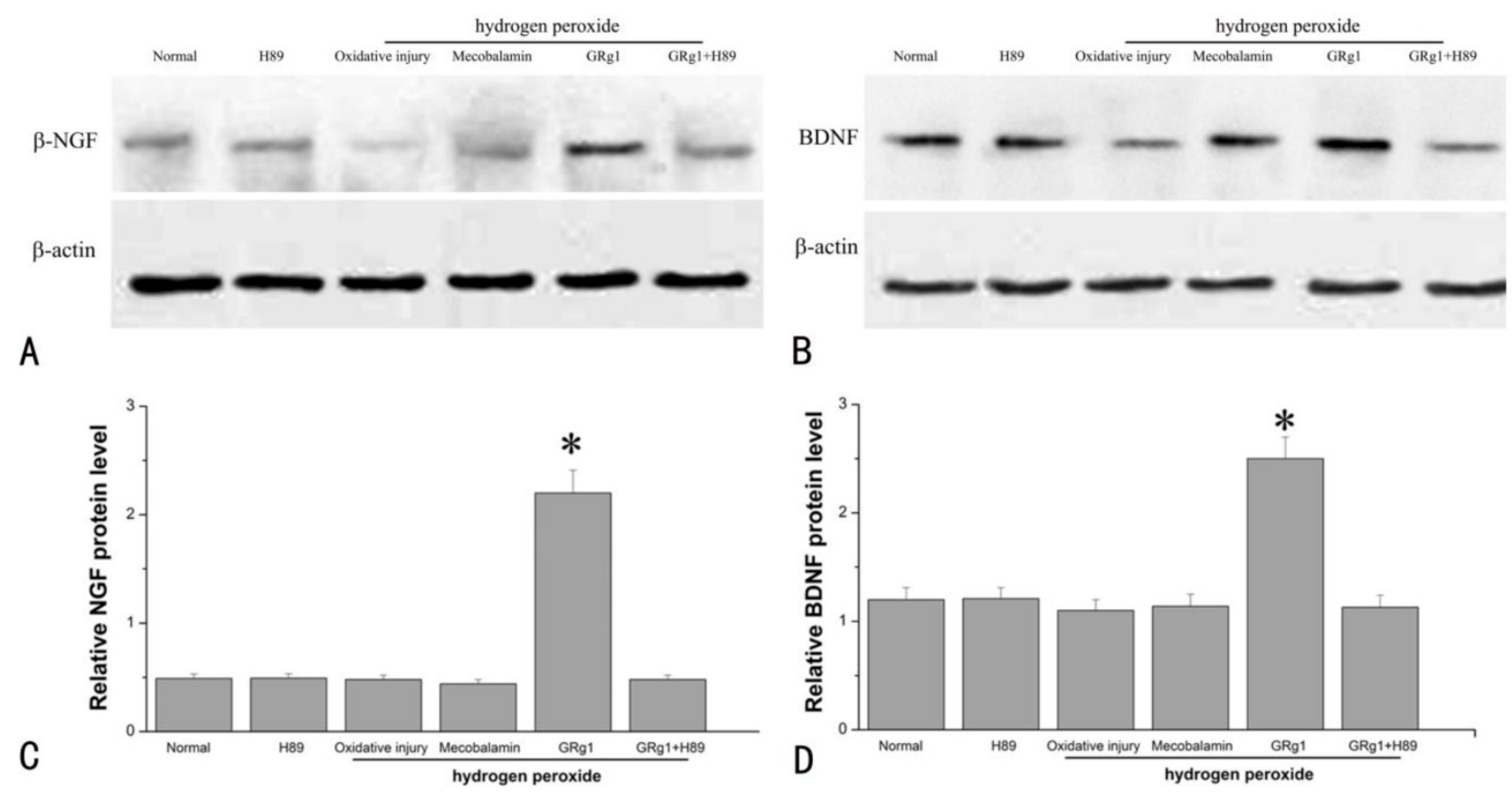

Fig 7. The protein levels of NGF (A, C) and BDNF (B, D) in SCs after hydrogen peroxide-induced oxidative injury. $* p<0.05$ for the comparison with normal group, oxidative injury group, or mecobalamin group.

At the protein level, the expression of NGF and BDNF was significantly higher in GRg1 treated SCs when compared to the cells cultured under normal condition, the cells cultured with hydrogen peroxide, or the cells cultured in the presence of hydrogen peroxide and Mecobalamin ( $p<0.05$, Fig. 7 A, C; $p<0.05$, Fig. 7 B, D). No significance was observed at the protein level of NGF and BDNF among the cells cultured under normal condition, the cells cultured with hydrogen peroxide, and the cells cultured in the presence of hydrogen peroxide and mecobalamin $(p>$ 0.05, Fig. 7 A-D). However, the beneficial effect of GRg1 on NTFs expression was abolished by pre-incubation with H89 at the protein level (Fig. 7 A-D).
We further analyzed the secretion of NGF and BDNF by SCs. It was found that hydrogen peroxide significantly $(p<0.05$, Fig. 8 A; $p<0.05$, Fig. 8 B) decreased the secretion of NGF and BDNF by SCs, with a decrease of $28.7 \%$ and $36.8 \%$ compared to that in SCs cultured under normal condition. When mecobalamin was added to the hydrogen peroxide-treated SCs, the secretion of NGF and BDNF was still lower compared to that in the cells cultured under normal condition $(p$ $<0.05$, Fig. 8 A; $p<0.05$, Fig. 8 B). However, when GRg1 was added to the hydrogen peroxide-treated SCs, the secretion of NGF and BDNF was significantly increased by GRg1, with an increase of $58.5 \%$ and $63.2 \%$ compared to that in the cells cultured under normal condition, with an increase of $122.4 \%$ and 
$158.2 \%$ compared to that in the cells cultured with hydrogen peroxide, and an increase of $85.5 \%$ and $106.0 \%$ compared to that in the cells cultured in the presence of hydrogen peroxide and mecobalamin $(p<$ 0.05 , Fig. 8 A; $p<0.05$, Fig. 8 B). However, the beneficial effect of GRg1 on NTFs secretion was abolished by pre-incubation with $\mathrm{H} 89$ at the protein level (Fig. 8 A, B).

\section{GRg I attenuates oxidative stress in crush in- jury model of sciatic nerve in rat}

The level of oxidative stress of the nerve tissue after crush injury was estimated by measuring MDA level, SOD activity, CAT activity and GSH level. As shown in Fig. 9 A, the MDA level in the cursh injury group was significantly higher than that in normal group, indicating increased lipid peroxidation after crush nerve injury. When administrated with GRg1, the MDA levels were significantly decreased $(p<0.05$, Fig. 9 A).

The SOD activity, CAT activity and GSH level were measured to investigate the oxidative stress induced by crush injury. It was found that SOD activity, CAT activity and GSH level in the crush injury group was significantly lower than that in normal group $(p<$ 0.05, Fig. 9 B, C, D), indicating decreased antioxidant activity after crush nerve injury. When administrated with GRg1, the SOD activity, CAT activity and GSH level were significantly increased $(p<0.05$, Fig. 9 B, C, D).
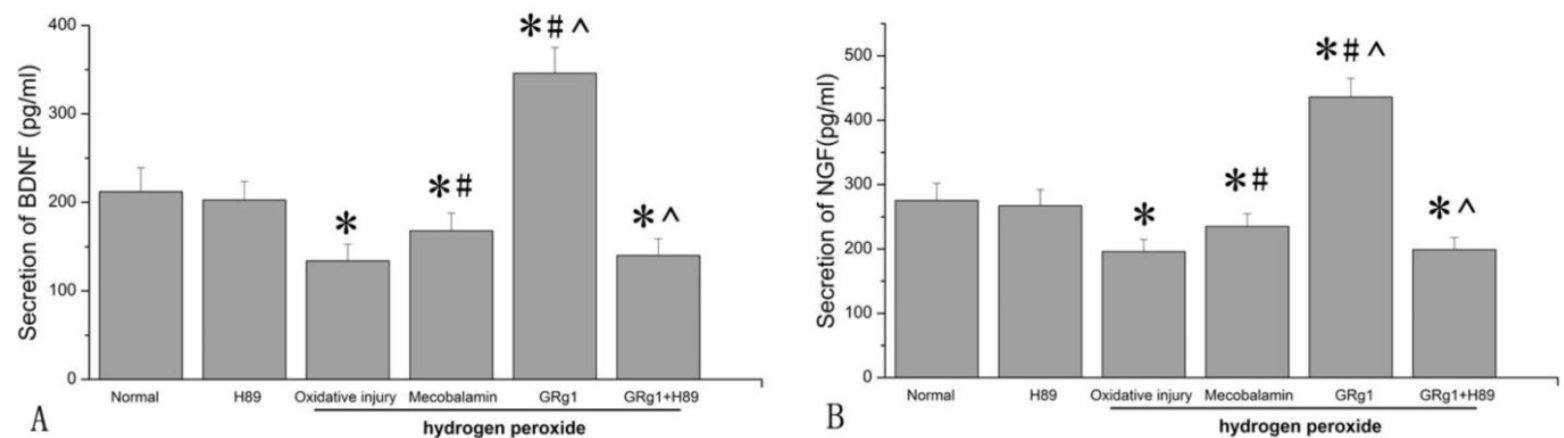

Fig 8. The secretion of NGF (A) and BDNF (B) in SCs after hydrogen peroxide-induced oxidative injury. ${ }^{*} p<0.05$ for the comparison with normal group. ${ }^{\#}<0.05$ for the comparison with oxidative injury group. $\wedge^{\wedge}<0.05$ for the comparison with mecobalamin group.
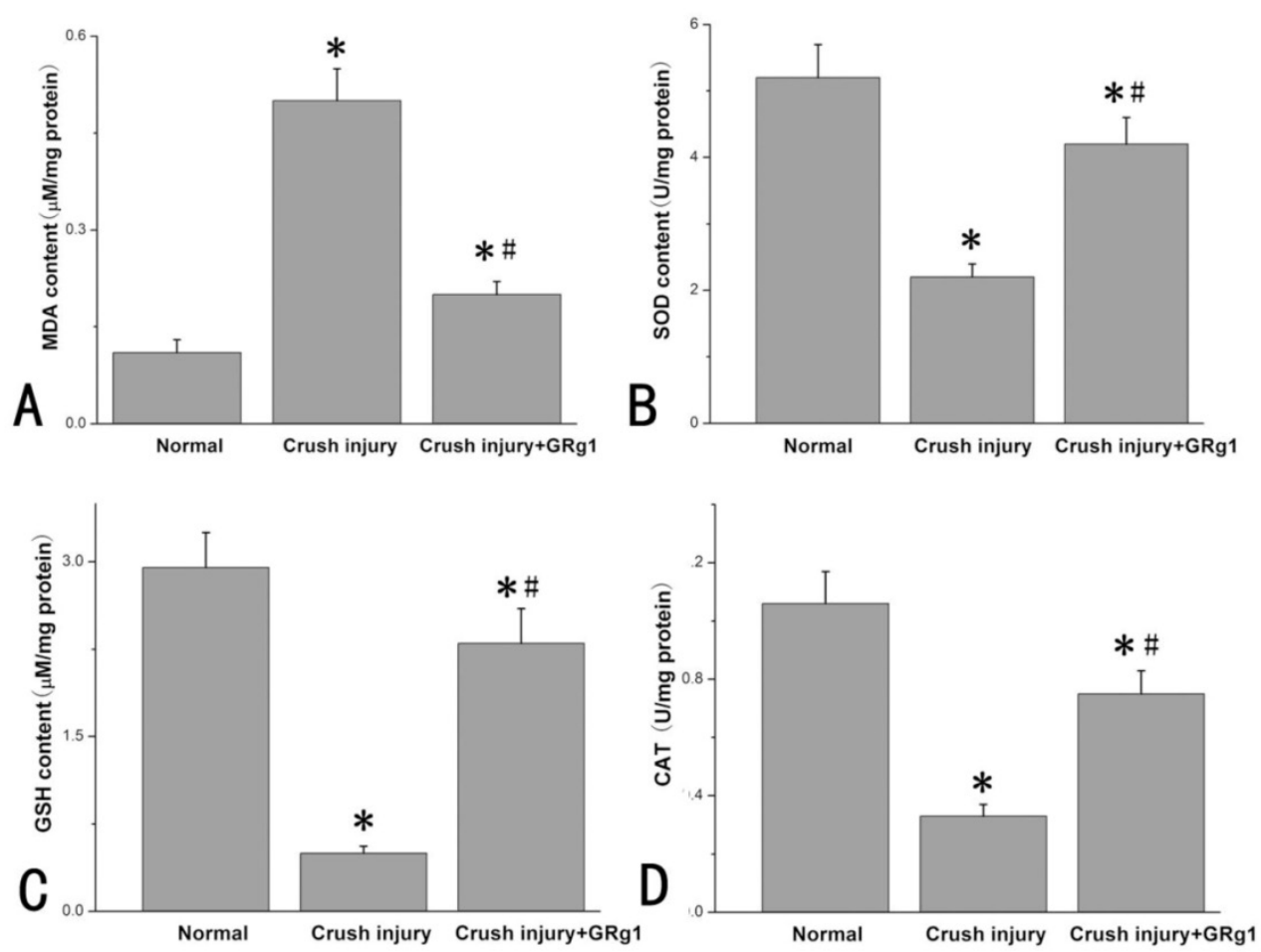

Fig 9. The MDA level (A), SOD activity (B), GSH level (C), and CAT activity (D) in each group two weeks after crush injury. ${ }^{*} p<0.05$ for the comparison with normal group. ${ }^{*} p<0.05$ for the comparison with crush injury group. 


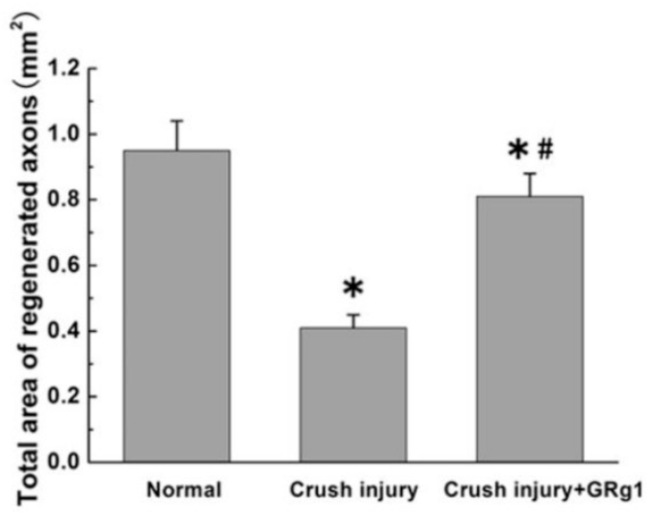

A

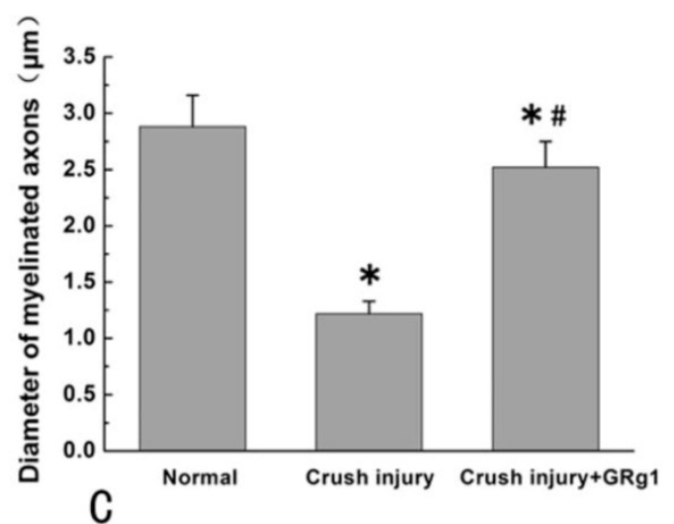

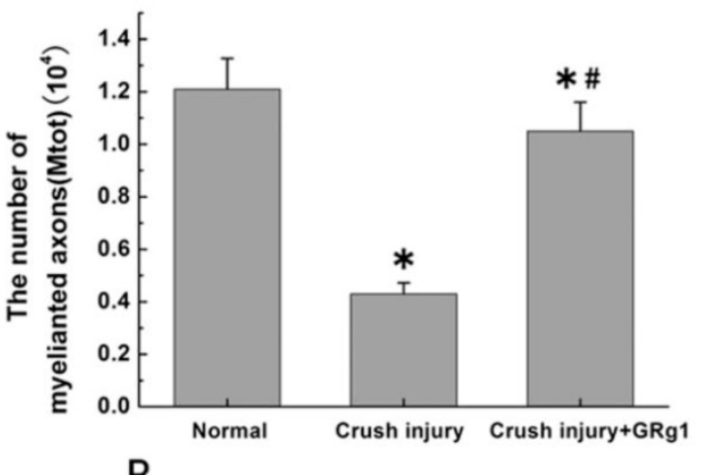

B

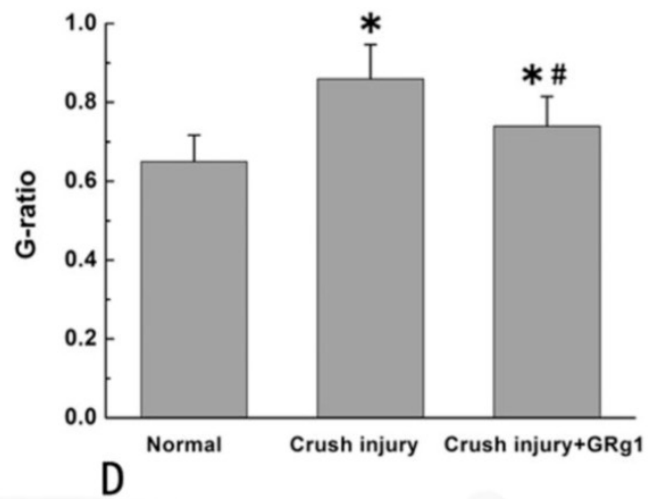

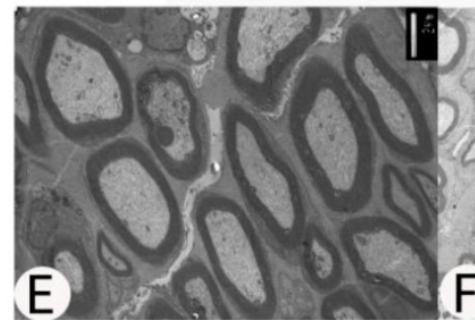

Normal

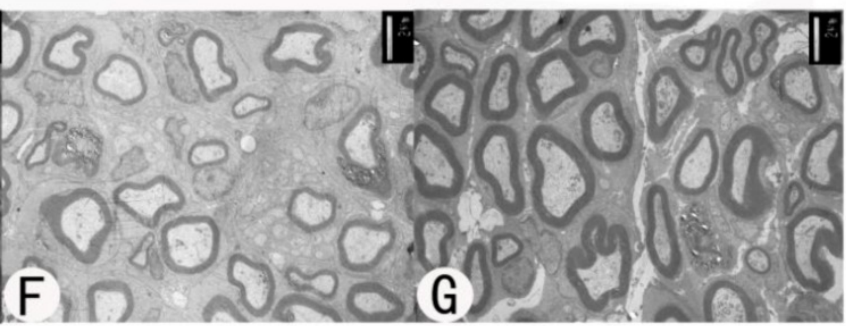

Crush injury
Crush injury+GRg1

Fig 10. The morphometric values (A, B, C and D) and representative images of transverse sectioned injured nerve by TEM (E, F and G) in all groups at 4 weeks after treatment.

\section{GRg I promotes nerve regeneration after crush injury of sciatic nerve in rats}

Morphometric analysis was used to estimate the beneficial effect of GRg1 on nerve regeneration after crush injury. Four weeks after surgery, mean diameter of nerve fibers, the total number of myelinated axons per nerve transverse section and total area of regenerated axons in the GRg1 group were significantly larger (or higher) than those in the crush injury group ( $p<0.05$, Fig. $10 \mathrm{~A}-\mathrm{C}, \mathrm{E}-\mathrm{G})$. In addition, the value of G-ratio (an indicator of myelination) was significantly better in GRg1 group than that in crush injury group $(p<0.05$, Fig. $10 \mathrm{D}-\mathrm{G})$.

\section{Discussion}

Our previous study has shown that GRg1 is ca- pable of promoting peripheral nerve regeneration and functional recovery after sciatic nerve injuries in rats [7]. However, the mechanism underlying the beneficial effect of GRg1 on peripheral nerve regeneration is currently unclear. The possible effect of GRg1 on SCs which were subjected to oxidative injury might contribute, at least in part, to the beneficial effect of GRg1 on nerve regeneration. The present study found that GRg1 is capable of helping SCs recover from hydrogen peroxide-induced oxidative injury and inhibiting the proapoptotic effect induced by hydrogen peroxide. In addition, our result showed that GRg1 not only increased the mRNA levels and protein levels of NGF and BDNF, but also enhanced their secretion in SCs after hydrogen peroxide treatment, indicating that GRg1 is able to enhance the biological activities of SCs 
after oxidative injury. Further studies showed that pre-incubation with H89 (PKA inhibitor) could inhibit those effects mentioned above, indicating the involvement of PKA pathway in the antioxidant effect and NTFs-promoting effect of GRg1. Furthermore, our in vivo study using a crush nerve injury model showed that GRg1 was capable of promoting nerve regeneration and inhibiting oxidative stress. The results partially confirm and validate the antioxidant effect and beneficial effect of GRg1 in vitro.

Oxidative injury is thought to be one of the main contributing factors to neural damage after injury [11-12]. Oxidants can traverse cell membranes to increase reactive oxygen species (ROS) and lipid peroxidation, activate different proteins, and lead to DNA damage [23-25]. It has been shown that SCs, as an important component of the peripheral nervous system, are also the target of various oxidative stresses [13-15]. Previous study has shown that oxidative injury to SCs is able to induce apoptosis in a dose and time dependent manner via the mitochondrial pathway [26]. In addition, oxidative injuries to axotomized neurons, such as increased production of ROS and nitric oxide (NO), have been increasingly recognized after peripheral nerve injury [27-30]. All these findings indicate that oxidative injury to SCs and axotomized neurons might be important processes during peripheral nerve injury. SCs possess important physiological functions during nerve repair, such as producing NTFs. Maintaining functional SCs might be important for nerve regeneration. Therefore, anti-oxidative therapeutic strategy holds the potential to treat peripheral nerve injury. Ginsenoside Rg1, a natural product exacted from Panax ginseng, has a notable anti-oxidative activity $[2,4,16$, 17]. Thus far, the beneficial effect of GRg1 on neurons or neuron-like cells has been extensively reported. It has been shown that pretreatment with GRg1 markedly reduces the generation of dopamine-induced ROS and the release of mitochondrial cytochrome $\mathrm{c}$ into the cytosol, and subsequently inhibits the activation of caspase- 3 in PC-12 cells, indicating that Rg1 attenuates dopamine-induced apoptotic cell death through suppression of intracellular oxidative stress [3-4]. GRg1 has also been shown to reduce the hydrogen peroxide-induced injury in PC12 cells via down-regulating NF-KB (nuclear factor kappa B) signaling pathway as well as Akt (Protein Kinase B, PKB) and extracellular signal-regulated kinase $1 / 2$ (ERK1/2) activation [18]. In addition, GRg1 can reduce MPTP (1-methyl-4-phenyl-1,2,3,6tetrahydropyridine) induced substantianigra neuron loss by suppressing oxidative stress, as well as blocking of JNK (c-Jun N-terminal kinase) signaling cascade [2]. All these findings indicate the neuroprotec- tive and anti-oxidative effect of GRg1 on neurons or neuron-like cells, which might be one major contributing factor to its beneficial effect on nerve regeneration. As is widely known, diabetic neuropathy is characterized by increased oxidative stress at the injury site. Interestingly, GRg1 has been proved to possess anti-diabetic activity [31, 32]. Whether GRg1 is able to protect Schwann cells against oxidative stress under diabetic condition is an interesting question, which awaits investigations in future studies.

The oxidative injury of SCs has been increasingly recognized after peripheral nerve injury. It has been shown that hydrogen peroxide treatment is capable of inducing apoptosis in SCs, which was realized through the mitochondrial pathway under oxidative stress [26]. In the present study, we firstly found that the SOD, GSH and CAT were increased and MDA content was lowered by GRg1 in the hydrogen peroxide-treated SCs, indicating that GRg1 might be capable of reducing oxidative injury induced by hydrogen peroxide. In addition, the percentage of apoptotic SCs was significantly lower in the hydrogen peroxide-treated SCs which were incubated with GRg1, suggesting that GRg1 is capable of inhibiting proapoptotic effect of hydrogen peroxide. Further studies showed that GRg1 is able to partially reverse the decreasing effect of hydrogen peroxide on cell number and cell viability of SCs in the present study. All these findings indicate the beneficial effect of GRg1 on SCs which were subjected to hydrogen peroxide-induced oxidative injury, which might be still reversible. As PKA pathway has been found to be involved in the process of oxidative stress [33], H89 (a PKA inhibitor) was used to investigate the possible involvement of PKA pathway. The results showed that pre-incubation with H89 could inhibit those antioxidant effects of GRg1. Therefore, PKA pathway is involved in the antioxidant effect of GRg1. Further studies were needed to fully identify the molecular mechanism underlying the beneficial effect of GRg1 on SCs under oxidative exposure.

Hydrogen peroxide was widely used in previous researches on oxidative stress. According to the literatures, the concentration of hydrogen peroxide used in most of in vitro studies ranged from $0.4 \mathrm{M}$ to $0.6 \mathrm{M}$. In our preliminary experiment, we firstly examined the differences of oxidative state between the crush injury group and normal group. Then a series of concentration of hydrogen peroxide was used and the level of oxidative status was measured. Finally, we found that the concentration of $0.2 \%(0.0588 \mathrm{M})$ was able to induce oxidative injury comparable to that in vivo. Therefore, $0.2 \%$ was used in the present study. In addition, the concentration of hydrogen peroxide used in our research was low and the culture solution 
of SCs was replaced immediately after treatment of hydrogen peroxide. Therefore, the damage induced by hydrogen peroxide might be still reversible. However, different cell types with different concentration of $\mathrm{H}_{2} \mathrm{O}_{2}$ may lead to different results, which should be investigated in future studies.

NTFs, such as NGF, BDNF and neurotrophin-3, have been proved to exert important functions in nerve injury and regeneration. After peripheral nerve injury, SCs can synthesize NTFs to provide trophic support for regeneration of axons [8-9]. Our research provides the first direct experimental evidence that GRg1 can up-regulate mRNA expression and increase protein expression and secretion of NGF and BDNF in SCs after hydrogen peroxide-induced oxidative injury. Our finding is consistent with another study which demonstrated that GRg1 can promote expression of NTFs in normal primary SCs [21]. Our results indicate that GRg1 is able to enhance the biological activities of SCs after oxidative injury, which might account, at least in part, for the beneficial effect of GRg1 on peripheral nerve regeneration. H89 was used to investigate the possible involvement of PKA pathway. The results showed that pre-incubation with H89 could inhibit NTFs-promoting effects of GRg1, suggesting the involvement of PKA pathway in such a process.

GRg1 possesses dramatic antioxidant effects, and is capable of helping Schwann cells recover from hydrogen peroxide-induced oxidative insult. As is widely known that Schwann cells possess important physiological functions during peripheral nerve regeneration, including producing NTFs. Therefore, GRg1 might protect the Schwann cells and maintain its physiological function (producing NTFs) through its antioxidant effect. To further confirm this possibility, H89 (an inhibitor of PKA) was used in the present study, which was found to attenuate both the antioxidant effect and NTFs-enhancing effect of GRg1 on Schwann cells simultaneously after hydrogen peroxide. These findings suggest that PKA pathway was involved, at least in part, both in the process of antioxidant effect and NTFs-enhancing effect. Although these findings, the relationship between these two effects should be explored in more details in future works.

Mecobalamin is capable of promoting regeneration after nerve injuries, both in peripheral nervous system and central nervous system [34-35]. Mecobalamin has also been widely used clinically in the treatment of peripheral neuropathy, diabetic neuropathy etc. In addition, many studies concerning peripheral nerve regeneration chose mecobalamin as a positive control [36-37]. Therefore, in the present study, a mecobalamin group was included as a positive control to examine the impact of GRg1 on SCs after oxidative injury.

In our present study, a crush nerve injury model of SD rat was used to confirm and validate the in vitro data. The results showed that GRg1 might inhibit oxidative stress and promote nerve regeneration. Therefore, we presumed that GRg1 might increase peripheral nerve repair through its antioxidant effects. In addition, two weeks after crush injury, the level of oxidative stress was higher in injury group than that in normal group. This difference was similar to that in our in vitro study, which might partially explain the rationality of choosing a hydrogen peroxide model for the experiment.

In conclusion, GRg1 is capable of helping SCs recover from the oxidative insult induced by hydrogen peroxide via PKA pathway, which might be one contributing factor to the beneficial effect of GRg1 on nerve regeneration.

\section{Acknowledgements}

This research was supported by the Science and Key Technology Research and Development Program of Liaoning Province (No. 2011225041 and No. 2012225019), and "Twelfth Five-Year Plan" Scientific Research Funds Project of Chinese PLA (CWS11J209).

\section{Competing Interests}

The authors have declared that no competing interest exists.

\section{References}

1. Chen XC, Chen Y, Zhu YG, Fang F, Chen LM. Protective effect of ginsenoside Rg1 against MPTP-induced apoptosis in mouse substantianigra neurons. Acta Pharmacol Sin. 2002; 23(9): 829-34. [PubMed: 12230953]

2. Chen XC, Zhou YC, Chen Y, Zhu YG, Fang F, Chen LM. Ginsenoside Rg1 reduces MPTP-induced substantianigra neuron loss by suppressing oxidative stress. Acta Pharmacol Sin. 2005; 26(1): 56-62. [PubMed: 15659115]

3. Chen XC, Zhu YG, Wang XZ, Zhu LA, Huang C. Protective effect of ginsenoside $\operatorname{Rg} 1$ on dopamine-induced apoptosis in PC12 cells. Acta Pharmacol Sin. 2001; 22(8): 673-8. [PubMed: 11749836]

4. Chen XC, Zhu YG, Zhu LA, Huang C, Chen Y, Chen LM, Fang F, Zhou YC, Zhao CH. Ginsenoside Rg1 attenuates dopamine-induced apoptosis in PC12 cells by suppressing oxidative stress. Eur J Pharmacol. 2003; 473(1): 1-7. [PubMed: 12877931]

5. Leung KW, Yung KK, Mak NK, Chan YS, Fan TP, Wong RN. Neuroprotective effects of ginsenoside-Rg1 in primary nigral neurons against rotenone toxicity. Neuropharmacology. 2007; 52(3): 827-35. [PubMed: 17123556]

6. Lu MC, Lai TY, Hwang JM, Chen HT, Chang SH, Tsai FJ, Wang HL, Lin CC, Kuo WW, Huang CY. Proliferation- and migration-enhancing effects of ginseng and ginsenoside Rg1 through IGF-I- and FGF-2-signaling pathways on RSC96 Schwann cells. Cell BiochemFunct. 2009; 27(4): 186-92. [PubMed: 19326380]

7. Ma J, Li W, Tian R, Lei W. Ginsenoside Rg1 promotes peripheral nerve regeneration in rat model of nerve crush injury. Neurosci Lett. 2010; 478(2): 66-71. [PubMed: 20438804]

8. Frostick SP, Yin Q, Kemp GJ. Schwann cells, neurotrophic factors, and peripheral nerve regeneration. Microsurgery. 1998; 18(7): 397-405. [PubMed: 9880154]

9. Pearse DD, Pereira FC, Marcillo AE, Bates ML, Berrocal YA, Filbin MT, Bunge MB. cAMP and Schwann cells promote axonal growth and functional recovery after spinal cord injury. Nat Med. 2004; 10(6): 610-6. [PubMed: 15156204] 
10. Martin LJ, Kaiser A, Price AC. Motor neuron degeneration after sciatic nerve avulsion in adult rat evolves with oxidative stress and is apoptosis. J Neurobiol. 1999; 40(2): 185-201. [PubMed: 10413449]

11. Martin LJ, Price AC, McClendon KB, Al-Abdulla NA, Subramaniam JR, Wong PC, Liu Z. Early events of target deprivation/axotomy-induced neuronal apoptosis in vivo: oxidative stress, DNA damage, p53 phosphorylation and subcellular redistribution of death proteins. J Neurochem. 2003; 85(1): 234-47. [PubMed: 12641745]

12. Kobayashi M, Ishibashi S, Tomimitsu H, Yokota T, Mizusawa H. Proliferating immature Schwann cells contribute to nerve regeneration after ischemic peripheral nerve injury. Neuropathol Exp Neurol. 2012; 71(6): 511-9. [PubMed: 22588387]

13. Fukunaga M, Miyata S, Liu BF, Miyazaki H, Hirota $Y$, Higo S, Hamada Y, Ueyama S, Kasuga M. Methylglyoxal induces apoptosis through activation of p38 MAPK in rat Schwann cells. Biochem Biophys Res Commun. 2004; 320(3): 689-95. [PubMed: 15240103]

14. Iida H, SchmeichelAM, Wang Y, Schmelzer JD, Low PA. Schwann cell is a target in ischemia-reperfusion injury to peripheral nerve. Muscle Nerve. 2004; 30(6): 761-6. [PubMed: 15468335]

15. Shokouhi G, Tubbs RS, Shoja MM, Roshangar L, Mesgari M, Ghorbanihaghjo A, Ahmadi N, Sheikhzadeh F, Rad JS. The effects of aerobic exercise training on the age-related lipid peroxidation, Schwann cell apoptosis and ultrastructural changes in the sciatic nerve of rats. Life Sci. 2008; 82(15-16): 840-6. [PubMed: 18336840]

16. Gao QG, Chen WF, Xie JX, Wong MS. Ginsenoside Rg1 protects against 6-OHDA-induced neurotoxicity in neuroblastoma SK-N-SH cells via IGF-I receptor and estrogen receptor pathways. J Neurochem. 2009; 109(5): 1338-47. [PubMed: 19476546]

17. Ge KL, Chen WF, Xie JX, Wong MS. Ginsenoside Rg1 protects against 6-OHDA-induced toxicity in MES23.5 cells via Akt and ERK signaling pathways. J Ethnopharmacol. 2010; 127(1): 118-23. [PubMed: 19799986]

18. Liu Q, Kou JP, Yu BY. Ginsenoside Rg1 protects against hydrogen peroxide-induced cell death in PC12 cells via inhibiting NF-KB activation. Neurochem Int. 2011; 58(1): 119-25. [PubMed: 21078355]

19. Yu SH, Huang HY, Korivi M, Hsu MF, Huang CY, Hou CW, Chen CY, Kao CL, Lee RP, Lee SD, Kuo CH. Oral Rg1 supplementation strengthens antioxidant defense system against exercise-induced oxidative stress in rat skeletal muscles. J IntSoc Sports Nutr. 2012; 9(1): 23. [PubMed: 22607394]

20. Korivi M, Hou CW, Huang CY, Lee SD, Hsu MF, Yu SH, Chen CY, Liu YY, Kuo CH. Ginsenoside-Rg1 Protects the Liver against Exhaustive Exercise-Induced Oxidative Stress in Rats. Evid Based Complement Alternat Med. 2012; 2012: 932165. [PubMed: 21941591]

21. Liang W, Ge S, Yang L, Yang M, Ye Z, Yan M, Du J, Luo Z. Ginsenosides $\mathrm{Rb} 1$ and $\mathrm{Rg} 1$ promote proliferation and expression of neurotrophic factors in primary Schwann cell cultures. Brain Res. 2010; 1357: 19-25. [PubMed: 20682297]

22. Huang $\mathrm{J}, \mathrm{Hu} X, \mathrm{Lu} \mathrm{L}, \mathrm{Ye} \mathrm{Z}, \mathrm{Zhang} \mathrm{O}$, Luo Z. Electrical regulation of Schwann cells using conductive polypyrrole/chitosan polymers. J Biomed Mater Res A. 2010; 93(1): 164-74. [PubMed: 19536828]

23. Chan $\mathrm{PH}$. Reactive oxygen radicals in signaling and damage in the ischemic brain. J Cereb Blood Flow Metab. 2001; 21(1): 2-14. [PubMed: 11149664]

24. Lewén A, Matz P, Chan PH. Free radical pathways in CNS injury. J Neurotrauma. 2000; 17(10): 871-90. [PubMed: 11063054]

25. Loh KP, Huang SH, De Silva R, Tan BK, Zhu YZ. Oxidative stress: apoptosis in neuronal injury. Curr Alzheimer Res. 2006; 3(4): 327-37. [PubMed: 17017863]

26. Luo X, Chen B, Zheng R, Lin P, Li J, Chen H. Hydrogen peroxide induces apoptosis through the mitochondrial pathway in rat Schwann cells. NeurosciLett. 2010; 485(1): 60-4. [PubMed: 20813162]

27. Bowe CM, Hildebrand C, Kocsis JD, Waxman SG. Morphological and physiological properties of neurons after long-term axonal regeneration: observations on chronic and delayed sequelae of peripheral nerve injury. J Neurol Sci. 1989; 91(3): 259-92. [PubMed: 2769297]

28. Clarke D, Richardson P. Peripheral nerve injury. Curr Opin Neurol. 1994; 7(5): 415-21. [PubMed: 7804462]

29. Kubo T, Yamashita T, Yamaguchi A, Hosokawa K, Tohyama M. Analysis of genes induced in peripheral nerve after axotomy using cDNA microarrays. J Neurochem. 2002; 82(5):1129-36. [PubMed: 12358760]

30. Zochodne DW, Levy D. Nitric oxide in damage, disease and repair of the peripheral nervous system. Cell MolBiol (Noisy-le-grand). 2005; 51(3): 255-67. [PubMed: 16191393]

31. Lee HM, Lee OH, Kim KJ, Lee BY. Ginsenoside Rg1 promotes glucose uptake through activated AMPK pathway in insulin-resistant muscle cells. Phytother Res. 2012 Jul;26(7):1017-22

32. Kim SJ, Yuan HD, Chung SH. Ginsenoside Rg1 suppresses hepatic glucose production via AMP-activated protein kinase in HepG2 cells. Biol Pharm Bull. 2010;33(2):325-8.
33. Wang Y, Kuro-o M, Sun Z. Klotho gene delivery suppresses Nox2 expression and attenuates oxidative stress in rat aortic smooth muscle cells via the cAMP-PKA pathway. Aging Cell. 2012 Jun;11(3):410-7.

34. Okada K, Tanaka H, Temporin K, Okamoto M, Kuroda Y, Moritomo H, Murase T, Yoshikawa H. Methylcobalamin increases Erk1/2 and Akt activities through the methylation cycle and promotes nerve regeneration in a rat sciatic nerve injury model. Exp Neurol. 2010 Apr;222(2):191-203.

35. Kuwabara S, Nakazawa R, Azuma N, Suzuki M, Miyajima K, Fukutake $\mathrm{T}$, Hattori T. Intravenous methylcobalamin treatment for uremic and diabetic neuropathy in chronic hemodialysis patients. Intern Med. 1999 Jun;38(6):472-5.

36. Jiang M, Zhuge X, Yang Y, Gu X, Ding F. The promotion of peripheral nerve regeneration by chitooligosaccharides in the rat nerve crush injury model. Neurosci Lett. 2009 May 1;454(3):239-43.

37. Yuan Y, Shen H, Yao J, Hu N, Ding F, Gu X. The protective effects of Achyranthes bidentata polypeptides in an experimental model of mouse sciatic nerve crush injury. Brain Res Bull. 2010 Jan 15;81(1):25-32. 